\title{
Nested presuppositions: A manipulative type of informative presupposition
}

\author{
Mohyi Eldeen Maziad, PhD, University of Cambridge, maziad.mohyi@gmail.com
}

\begin{abstract}
This paper introduces the new pragmatic concept of Nested Presuppositions (NestPs) and develops a relevance-theoretic account that explains its cognitive dynamics and manipulative mechanisms. The first section lays necessary theoretical foundations, by defining pragmatic presupposition, compiling a taxonomy of the types of presupposition and their triggers, identifying and critiquing research gaps in eight of the most relevant studies and drawing the conclusion that none of the existing definitions or accounts of pragmatic presupposition can adequately capture the manipulative characteristics and mechanisms of the instances of informative presupposition at issue. In section two, I shall introduce the concept of NestPs as the filler of those gaps, grounding it in Textual Rhetoric and Relevance Theory and highlighting its defining characteristic of information structures, i.e. how the message is segmented and its degrees of prominence and suppression are assigned in order to achieve strategic goals. I further problematize the relationship between NestPs, on the one hand, and informativeness and manipulation, on the other, in light of Gricean and Relevance-Theoretic linguistics, establishing that NestPs are inherently manipulative. I finally expound the manipulative dynamics of NestPs, in terms of the information processing mechanisms they employ, by capitalizing on the concepts of Ostensive Stimulus, Cognitive Principle of Relevance, Principle of Optimal Relevance and Comprehension Procedure, and suggesting the two new mechanisms of Cognitive Underpassing and Structure-Content Cognitive Conflict.
\end{abstract}

\section{Keywords}

nested presuppositions, pragmatic presupposition, cognitive linguistics, manipulation, relevance theory, Arab Spring speeches, ben Ali, Mubarak, cognitive pragmatics, and Critical Discourse Analysis

\section{Introduction}

This paper introduces the new pragmatic concept of Nested Presuppositions (henceforth NestPs) and develops a relevance-theoretic account that explains its cognitive dynamics and manipulative mechanisms. The first section is a literature review that outlines some competing definitions of pragmatic presupposition, compiles a taxonomy of the types of pragmatic presupposition and their triggers, discusses five of the key (problematic) properties of presupposition and establishes the need for NestPs by identifying and critiquing research gaps in eight of the most relevant studies in the field. In the second section, I shall introduce the new concept of NestPs, ground it in Textual Rhetoric and Relevance Theory, define it in terms of information structuring and packaging and elucidate my definition, with three il- lustrative examples, two of which are put to the classical tests of pragmatic presupposition. In section three, I sketch a cognitive account that explains the manipulative dynamics and functions of NestPs, in terms of the four relevance-theoretic concepts of Ostensive Stimulus, Cognitive Principle of Relevance, Principle of Optimal Relevance and Comprehension Procedure, as well as the two newly suggested mechanisms of Cognitive Underpassing and Structure-Content Cognitive Conflict. I conclude with some recommendations for further research.

\section{Literature Review}

\subsection{What is pragmatic presupposition?}

Although the literature on presupposition almost exceeds that written on any other topic in Pragmatics, a great deal of 
it is "obsolete and sterile" (Levinson 1983: 167), and has failed to reach a consensus on even a definition or a set of defining properties (Peccei 1999: 19). Aspects of disagreement include whether presupposition is a relation between sentences, statements or speakers and assumptions (Frege 1892; Strawson 1950; 1952); whether the locus of presupposition is speakers, sentences or both (Keenan 1971; Brown \& Yule 1983; Levinson 1983; Yule 1996; Simons 2003; Richardson 2007; Stalnaker 2011); and whether presupposition refers to a specific homogenous phenomenon or a range of heterogeneous phenomena (Levinson 1983; Green 1989; Huang 2007). These competing views have yielded many conflicting definitions of presupposition, each tackling it from a different perspective.

One of the most comprehensive definitions of presupposition is that proposed by Stalnaker (1972: 387-8) in which he argues that to "presuppose a proposition in the pragmatic sense is to take its truth for granted, and to presume that others involved in the context do the same." He recast this definition, two years later, in the following Grice-like formula:

A proposition $\mathrm{P}$ is a pragmatic presupposition
of a speaker in a given context just in case the
speaker assumes or believes that P, assumes
or believes that his addressee assumes or be-
lieves that P, and assumes or believes that his
addressee recognizes that he is making these
assumptions, or has these beliefs. (1974: 473)

The importance of the conditions of sincerity and cooperation, which Stalnaker foregrounded in the second definition, are also underscored by Verschueren (1999) who confirms that for an utterance to be meaningful and successful, its presupposed propositions must be shared as common knowledge by both the speaker and the hearer.

\subsection{Types of presupposition and presuppositional triggers}

In spite of their disagreement on a definition of presupposition, researchers have agreed on identifying some prototypical ex- amples that represent the different types of presupposition and their presuppositional triggers, the latter being the linguistic "inducers" or "clues" used to communicate the meaning implied in a presupposition.

Out of the thirty-one types of presuppositional triggers "isolated" by Karttunen (1973; 1974), Levinson selected only thirteen and considered them "the core of the phenomena that are generally considered presuppositional": definite descriptions, factive verbs, implicative verbs, change of state verbs, iterative verbs, verbs of judging, temporal clauses, cleft sentences, implicit clefts with stressed constituents, comparisons and contrasts, non-restrictive relative clauses, counterfactual conditionals, and questions (1983: 184).

There are less comprehensive classifications of presuppositional triggers: Short (1989) classified them into existential, linguistic and pragmatic; Yule (1996) categorized them into existential, factive, lexical, structural, non-factive and counter-factual and Maingueneau (1996) reduced them to two broad categories of presuppositions triggered by linguistic structures and presuppositions triggered by the relation between utterance and context.

There has not been yet an exhaustive list of all the types of presupposition and their triggers. Table 1 is a compilation of all the types and triggers provided by Levinson (1983), Yule (1996) and Huang (2007).

\section{3 (Problematic) Properties of informative presupposition}

\subsubsection{Common ground}

Common Ground refers to "what is taken by the speaker to be the common ground of the participants in the conversation, what is treated as their common knowledge or mutual knowledge" (Stalnaker 1978: 321). It is thus one of the two basic conditions required for establishing presupposition: an "utterance A pragmatically presupposes a proposition B iff A is appropriate only if B is mutually known by participants" (Levinson 1983: 205). Common ground is typically associated with "participant-old" information, i.e. information that belongs to the set of common beliefs, values and 
Table 1: Types of presupposition and presuppositional triggers

\begin{tabular}{|c|c|c|c|}
\hline Type & Presuppositional Trigger & Details & Example \\
\hline $\begin{array}{l}\text { Specific } \\
\text { existential }\end{array}$ & $\begin{array}{l}\text {-Definite descriptions } \\
\text {-Definite noun phrases, a definite article, de- } \\
\text { monstrative, possessive pronoun or s-genitive } \\
\text { followed by a noun phrase, or a proper noun }\end{array}$ & $\begin{array}{l}\text { Presupposition of existence; speaker commits } \\
\text { to the existence of the named entity }\end{array}$ & $\begin{array}{l}\text { John saw the } \\
\text { Unidentified } \\
\text { Flying Object }\end{array}$ \\
\hline \multirow{5}{*}{$\begin{array}{l}\text { Structural/ } \\
\text { Non-specific } \\
\text { existential }\end{array}$} & -WH-questions & \multirow{3}{*}{$\begin{array}{l}\text {-Certain linguistic structures are regularly and } \\
\text { conventionally analysed as presupposing that } \\
\text { some part of the structure is already true }\end{array}$} & \multirow{2}{*}{$\begin{array}{l}\text {-When did you } \\
\text { last hit your } \\
\text { wife? }\end{array}$} \\
\hline & \multirow{2}{*}{$\begin{array}{l}\text {-Cleft, or } \\
\text {-pseudo-cleft sentences }\end{array}$} & & \\
\hline & & & -was/wasn't \\
\hline & \multirow[t]{2}{*}{-Implicit clefts with stressed constituents } & \multirow[t]{2}{*}{-Linguistics was/wasn't invented by CHOMSKY } & $\begin{array}{l}\text { John who } \\
\text { kissed Mary. } \\
\text {-what John lost } \\
\text { was/wasn't his } \\
\text { wallet }\end{array}$ \\
\hline & & & $\begin{array}{l}\text {-John did/didn't } \\
\text { compete in the } \\
\text { OLYMPICS }\end{array}$ \\
\hline \multirow[t]{2}{*}{ Factive } & $\begin{array}{l}\text {-Factive emotive verbs } \\
\text { Example: regret, be sorry, be glad, be sad that, } \\
\text { be proud that, be indifferent }\end{array}$ & $\begin{array}{l}\text {-The information following certain verb phrases } \\
\text { is treated as fact. } \\
\text {-Indicates emotional attitude towards fact. }\end{array}$ & \multirow[t]{2}{*}{$\begin{array}{l}\text {-I regretted } \\
\text { telling him the } \\
\text { name of my } \\
\text { friend }\end{array}$} \\
\hline & $\begin{array}{l}\text {-Factive epistemic/Cognitive factive verbs, Ex- } \\
\text { ample: realize, know, be aware of, be obvious }\end{array}$ & -Indicates knowledge of fact & \\
\hline Non-factive & $\begin{array}{l}\text {-Non-factive verbs } \\
\text { Example: believe, suppose, pretend, imagine, } \\
\text { dream, claim }\end{array}$ & $\begin{array}{l}\text {-The information following certain verb phrases } \\
\text { is treated as untrue. }\end{array}$ & $\begin{array}{l}\text { - He claimed that } \\
\text { I was driving } \\
\text { fast }\end{array}$ \\
\hline Counterfactual & -Counterfactual conditionals & $\begin{array}{l}\text {-The information presented is presupposed to be } \\
\text { the opposite of what is true. }\end{array}$ & $\begin{array}{l}\text {-If I had been } \\
\text { driving fast, } \\
\text { I might have } \\
\text { crashed }\end{array}$ \\
\hline \multirow[t]{7}{*}{ Lexical/Other } & $\begin{array}{l}\text {-Implicative verbs } \\
\text { Example: manage, forget to, happen, avoid, } \\
\text { happened to }\end{array}$ & \multirow[t]{3}{*}{$\begin{array}{l}\text {-The use of a particular expression is taken to } \\
\text { presuppose another unstated concept. }\end{array}$} & \multirow[t]{3}{*}{$\begin{array}{c}-1 \text { managed to } \\
\text { drive fast }\end{array}$} \\
\hline & $\begin{array}{l}\text {-Aspectual/Change-of-state verbs } \\
\text { Example: stop, begin, start, continue, carry on, } \\
\text { cease, take, leave, enter, come, go, arrive }\end{array}$ & & \\
\hline & $\begin{array}{l}\text {-Iteratives (adverbs and verbs) Example: again, } \\
\text { any more, return, repeat, another time, to come } \\
\text { back, restore, for the nth time }\end{array}$ & & \\
\hline & $\begin{array}{l}\text {-Temporal clauses } \\
\text { Example: subordinate clauses beginning with } \\
\text { when, before, while, since, after, during, } \\
\text { whenever, as }\end{array}$ & $\begin{array}{l}\text {-Marked by stress/other prosodic means } \\
\text {-Marked by particles, e. g. too, back, in return } \\
\text {-Marked by comparative constructions }\end{array}$ & $\begin{array}{l}\text {-I stopped driving } \\
\text { fast }\end{array}$ \\
\hline & $\begin{array}{l}\text {-Verbs of Judging } \\
\text { Example: accuse, criticise }\end{array}$ & \multirow[t]{4}{*}{\begin{tabular}{|c|}
-The Proto-Harrappans, who flourished $2800-$ \\
2650 B.C., were/were not great temple builders
\end{tabular}} & $\begin{array}{l}\text {-When I drove } \\
\text { fast, I skidded }\end{array}$ \\
\hline & -Comparisons and contrasts & & \\
\hline & \multirow[t]{2}{*}{-Non-restrictive relative clauses } & & $\begin{array}{l}\text {-Marianne called } \\
\text { Adolph a male } \\
\text { chauvinist, then } \\
\text { HE insulted HER } \\
\text {-Carol is/isn't a } \\
\text { better linguist } \\
\text { than Barbara }\end{array}$ \\
\hline & & & \\
\hline
\end{tabular}


knowledge shared by both interlocutors and is consistent with the "pre-constructed" propositions assumed as "context" (Stalnaker 1978; Gazdar 1979; Levinson 1983; Fairclough 1995; Chapman \& Routledge 1999).

In spite of this consensus on the importance of Common Ground in pragmatic presupposition, I consider it problematic because, as I will explain in detail in section 5, NestPs do not always communicate common ground, participant-old knowledge.

\subsubsection{Informative presupposition and presuppositional accommodation}

This stipulation that the information carried by pragmatic presupposition has to be participant-old is challenged by the counter-argument that presuppositions have "informative" usages: when the presupposed utterance introduces participant-new information not shared by the hearer, and imposes an adjustment on their common ground (Karttunnen 1974; Lewis 1979; Gauker 1997; 1998). This informative aspect of presupposition is formulated in the Accommodation Rule, according to which listeners "accommodate" the new presupposed information by fitting it into the background they share with the speaker:

If at time $t$ something is said that requires presupposition $\mathrm{P}$ to be acceptable and if $\mathrm{P}$ is not presupposed just before $t$, then - ceteris paribus and within certain limits - presupposition P comes into existence at t. (Lewis 1979: 340)

Accommodation Rule was criticised as being no more than a formulation of the problem, rather than an explanation of, or a solution to, it (Gauker 1997; Sbisà 1999). Figure 1 is a tentative schematic representation of presuppositional accommodation.

\subsubsection{Constancy under negation}

Constancy Under Negation is the property by which the presupposition of a statement survives negation and remains "constant" and "effective". Although it is considered one of the defining properties of presuppo-
Figure 1: Schematic representation of presuppositional accommodation

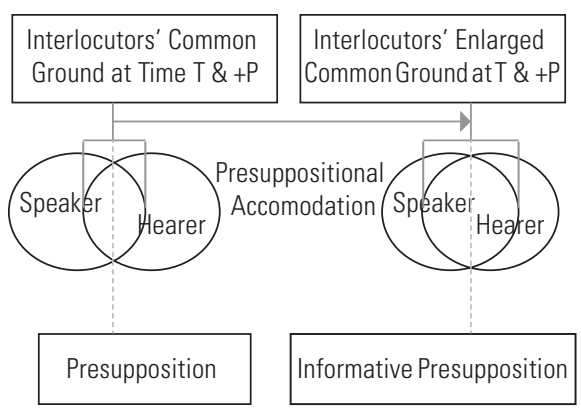

sition (Yule 1996; Verschueren 1999; Huang 2007), some scholars contend that it "is not in fact a rich enough definition to pick out a coherent, homogeneous set of inferences" (Levinson 1983: 185) and suggest replacing it with Defeasibility as "one of the crucial properties of presuppositional behaviour and one of the touchstones against which all theories of presupposition have to be assessed" (ibid: 186).

\subsubsection{Defeasibility}

Defeasibility is the "cancellation" or "evaporation" of presupposition (Levinson 1983; Huang 2007), which can arise in different scenarios and contexts, e.g. "immediate linguistic contexts" or "less immediate discourse contexts" (1983: 186). The contexts most relevant for the scope of this paper are when presuppositions contradict realworld knowledge, prevailing background assumptions, implicatures and (or) immediate inter- and (or) intra-sentential contexts.

\subsubsection{Projection}

Some linguistic expressions and environments are argued to allow presuppositions embedded in complex sentences to "pass up" or "project up" from their lower-level embedded phrase to the higher level of the whole sentence. The "complementizable predicates" that allow such a projection are called "holes", those that block it "plugs" and the intermediate ones "filters" (Karttunen 1973: 173-8). When embedded presuppositions fail to survive at the level of the complex sentence, the Projection 
Figure 2: $\quad$ Message segmentation in NestPs

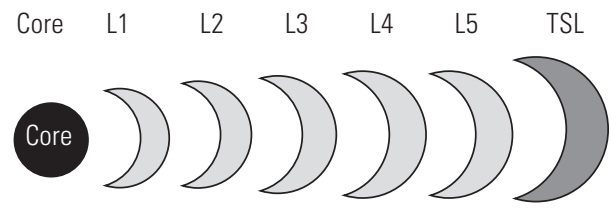

Problem (PP) arises. PP was accepted by some scholars, based on the Fregian compositional view that the overall meaning of an expression is a function of the total sum meaning of its parts (Yule 1996: 30 ), and rejected by others because of its vagueness and inadequacy to determine "which presuppositions of component clauses will [...] be inherited by the complex whole" (Levinson 1983: 191).

\subsection{Relevant literature on informative presupposition}

This section reviews and critiques eight of the most relevant studies to informative presupposition: Sbisà (1999) which highlights the persuasive and ideological uses of informative presupposition, Simons (2003, 2004) which ground informative presupposition in the cognitive sphere of Relevance Theory, de Saussure (2012) which attempts to explain presupposition in terms of Relevance Theory, and Capone (2017a, 2017b) and Macagno and Capone (2016a, 2016b) which fine-tune and develop the concept of common ground.

First, the ideological and persuasive usages of informative presupposition are highlighted by Sbisà, who draws the conclusion that informative presupposition serves a persuasive function and acts as a convenient carrier and transmitter of ideological content "when what is presupposed has to do with values, social norms or ideals, or with perspectives on facts which are proper to a specific social agent" (1999: 492). She further contends that these ideological and persuasive uses of informative presupposition cannot be explained adequately in terms of the concept of Presuppositional Accommodation (PA) with its binary distinction between presupposition proper and informative presupposition. The existence of many gradual and subtle distinctions between these two poles of PA, she argues, render the concept incapable of capturing the complicated processes involved in social communication. Sbisà thus suggests allowing presuppositions a "normative feature", by treating them "not as shared assumptions, but as assumptions which ought to be shared," because the persuasive use of presupposition is contingent upon the specific "normative or deontic features that presuppositional phenomena have" (ibid: 500).

Some questions were left unanswered by the important study of Sbisà (1999). For example, is it very practical to consider all the persuasive uses of presupposition communicative in the manner Sbisà did? When to consider informative presupposition persuasive and when to consider it manipulative? Under which of the five cases of the "supposedly shared status of presuppositions", listed by Sbisà (p. 498), are we to subsume the case of exploiting informative presupposition strategically in order to achieve manipulative goals, i.e. when the speaker does not hold the presupposed assumption and knows that the hearer does not hold it either, because the presupposed assumption is itself not satisfied by the "objective context"; nevertheless, the speaker presupposes the assumption in order to deliberately manipulate the hearer? Finally, does not the assumption that "we should not give separate accounts of presupposition proper and informative or persuasive presupposition" (ibid: 499), upon which Sbisà bases her argument, seem not to attribute due weight to the important factor of intentionality, without which Pragmatics would not function properly?

Secondly, a quantum leap in the investigation of presupposition was made by $\mathrm{Si}$ mons $(2003 ; 2004)$ who criticised previous semantic and pragmatic accounts of presupposition as mere "descriptive characterizations" and re-oriented the topic in Relevance Theory: defining the presuppositions of an utterance as the "propositions which the addressee must accept in order for the 
utterance to be relevant for her in the way intended by the speaker" (2003: 256).

Simons based her argument on Relevance theory, maintaining that the relevance of an utterance can lead to its acceptance as a presupposition. The most relevant proposition, i.e. the one inducing the principal contextual effect, is the strongest proposition that will be foregrounded in the utterance and treated as the maximal proposition. Any other propositions will be backgrounded and dealt with as secondary "non-maximal entailments". Presuppositions arise, Simons contends, when the acceptance of the backgrounded propositions becomes a prerequisite for the acceptance of the maximal entailment. Presupposition is thus viewed as a relevance requirement and presuppositions as propositions required for establishing relevance, either by being part of the context of the hearer or by being communicated as new but non-main-point propositions that are not the principal carriers of relevance (2004: 329-55).

Simons $(2003 ; 2004)$ made a contribution to the investigation of presupposition by tackling it from a cognitive perspective, but offered no explanation of the cognitive mechanisms involved in the relevancetheoretic presupposition or the manipulative potential of pragmatic presupposition.

Thirdly, the relevance-theoretic investigation of presupposition is further developed by de Saussure who defines presuppositions as "contents brought about by an utterance as pre-conditions not to meaning but to relevance" (2012: 38). He explains presupposition in terms of the "economy of information processing": employing the "Minimax Scales", i.e. the rules of minimising costs and maximising effects, to organize the cognitive processes involved in natural language processing (ibid: 39). De Saussure contends that since presuppositions are "incorporated in the cognitive environment of the hearer as preconditions to relevance," they are "shallowly processed", i. e. not subjected to discussion, critical evaluation or controls and filters of relevance (ibid: 47).
Although de Saussure (2012) develops a plausible cognitive account of presupposition, his treatment of presuppositions as "contents" seems to disregard the important role played by structure. This represents a real problem in NestPs which, as will be explained in detailed in the following section, are primarily manipulative because they disguise unshared, new-information "contents" and present them as presupposed, old-information contents, by carrying the former in structures typically associated with the latter and attacking the short-term and working memories of the hearer with multiple such structures. Presuppositions thus do not necessarily operate as old-information "contents" only, but also as cognitively taxing information structures.

Fourthly, the analysis of presupposition has been developed by Capone (2017a, 2017b) and Macagno and Capone (2016a, 2016b) who enriched it with new linguistic and argumentative perspectives and finetuned its central concept of common ground.

Linguistically, they grounded their approach on the theory of Polyphony (Ducrot 1984, a cited in Macagno \& Capone 2016a) which distinguishes different voices, assertions, and commitments within an utterance: an utterance may deploy a polyphony of conflicting voices arranged in complex structures of direct and indirect reports whose enunciators can be distinguished distinctively and held responsible for different implicit speech acts. The analysis of Macagno and Capone (2016a) is based on the two interrelated concepts of presumptions and commitments: it maintains that pragmatic presupposition is mainly based on common ground and possible accommodation, and explains the problematic relationship between presupposition triggers and pragmatic presuppositions in terms of the presumptive and non-presumptive polyphonic articulations of an utterance and the distinct commitments that ensue for the interlocutors.

The presumptive, polyphonic interpretation of an utterance distinguishes between two or more utterers: a first utterer, 
i.e. the speaker, and a voice representing a common opinion. The non-presumptive, polyphonic articulation consists of a free indirect report, in which the utterer reports the presuppositions indirectly by attributing them to a second voice that belongs to the speech community of the hearer.

When the presumed commitments deriving from the presumptive interpretation of an utterance conflict with its presumable stronger ones, the polyphony of the utterance is renegotiated, i.e. the utterance is no longer interpreted, presumptively, as expressing the point of view of the speaker, but, non-presumptively, as consisting of two or more voices: one stating the viewpoint of the speaker and the other(s) indirectly reporting another view point that the speaker does not hold as his/her commitments. That non-presumptive modification of the presumptive structure of an utterance distances the speaker from the presupposed propositions, treats them as quoted elements of discourse that do not result in any responsibility for the speaker, and hence does not hold the latter responsible for them. That polyphonic articulation of the implicit dialogical dimension of an utterance and its underlying structures can explain cases in which semantic presupposition triggers do not result in pragmatic presuppositions, i.e. the phenomena of presupposition suspension which arise when there is a discrepancy between the presumptive reading of an utterance and its non-presumptive meaning.

Capone et al. explained those phenomena of presupposition suspension as cases of non-presumptive, non-prototypical interpretation of utterances, whose presumptive, prototypical reading had failed to reconstruct the communicative intention of the speaker. Such a failure triggers a non-defaultive reading of the utterance, modifies its prototypical polyphony, allows the speaker to metalinguistically refuse the commitments resulting from the other voice(s), and initiates a non-automatic, complex mechanism of meaning explanation that aims at reconstructing the illocutionary force of the utterance, retrieving the logical form of the proposition, and ultimately establishing the communicative intention of the speaker.

That process of reconstructing the pragmatic structure of the utterance, which Capone et al. called reasoning from best interpretation, can be considered as an abductive pattern of microargumentation based on hierarchies of presumptions, as it involves a complex type of reasoning that compares, analyses, and weights the different possible linguistic and epistemic presumptions associated with the different interpretations of the expressed meaning as well as its co-textual and contextual information, in an attempt to find the best possible explanation of the communicative intention of the speaker. That interpretive reasoning process underlies the automatic relevance-theoretic mechanism of explicature which decodes, reconstructs, and explicates the implicated pragmatic meaning into a propositional one.

Capone (2017a, 2017b) and Macagno and Capone (2016a, 2016b) therefore fertilized the analysis of presupposition argumentatively and linguistically. Argumentatively, they analysed the pragmatic concept of "taking responsibility" for an utterance in terms of the argumentative concepts of "commitments" or "dialectical obligations", and explained some cases of presupposition suspension in terms of the two microargumentation mechanisms of presumptive reasoning and reasoning from best argumentation. Linguistically, their presumptive/non-presumptive polyphonic treatment of presupposition explained some of the phenomena of presupposition suspension in terms of the mechanism of explicature and the corresponding non-presumptive reasoning underlying it, allowed the reconstruction of the logical form of the illocutionary force of utterances, and accounted for the attribution of the commitments of the speaker and the hearer and the presumptions underlying it.

Nevertheless, that polyphonic treatment cannot account for cases of informative presupposition in which the speaker reports unsubstantiated, non-common- 
ground presumptions and (or) attributes them to a second voice in order not to distance her/himself from them or to evade responsibility for them, but to commit both her/himself as well as the hearers to that presumed content, and hence manipulate the latter deliberately by passing that unsubstantiated presumed content as agreed-upon, common-ground facts, in an argumentative move similar to that implied in the Aristotelian presumptive fallacy of petitio principii, i.e. presupposing a conclusion of an argument as its premises or assuming premises that are not likely to be known or admitted by the addressee (Schipper \& Schuh, 1960: 55-60). The polyphonic treatment of presupposition, therefore, cannot account for the manipulative instances of informative presupposition cited in the corpus of speeches at issue.

\section{Nested presuppositions}

\subsection{Theoretical framework}

\subsubsection{Textual Rhetoric}

The newly suggested concept of NestPs is inspired by Textual Rhetoric (TR): “(a) how to segment the message into units; (b) how to assign degrees of prominence or subordination; and (c) how to order the parts of the message" (Leech 1983: 64). This particular framework has been selected because it underscores the strategic role played by linguistic structures, not in their grammatical sense, but in their pragmatic force, i.e. how they are engineered to foreground, hide, frame, and (or) intermediate specific meanings.

\subsubsection{Relevance Theory}

Relevance Theory (RT) is a cognitive, psychological, inferential theory of communication that aims at interpreting utterances, as well as any other "ostensive stimulus", in terms of cognitive processes (Wilson 1998; Sperber \& Wilson 1985, 1995, 2002; Wilson \& Sperber 2004). RT is constructed upon three key concepts: The Cognitive Principle of Relevance (CGPR), the Communica- tive Principle of Relevance (CMPR) and the presumption of Optimal Relevance (OR).

CGPR states that human cognition is "geared to the maximisation of relevance" (Wilson \& Sperber 2004: 249), and CMPR assumes that every "ostensive stimulus conveys a presumption of its own optimal relevance" (ibid: 254). CMPR is thus based on the CGPR and the Gricean concept of Inferential Communication (IC) which considers communication "a process of inferential intention attribution” (ibid: 254). Wilson \& Sperber added an extra layer of intention to IC and called it Ostensive Inferential Communication (OIC), contending that it involves "a. The informative intention: The intention to inform an audience of something, [and] b. The communicative intention: The intention to inform the audience of one's informative intention" (ibid: 255). While the fulfilment of the communicative intention is a prerequisite for understanding, the fulfilment of the informative intention depends on whether the audience trusts the communicator or not, a condition not necessary for mere recognition. Every act of OIC is based on the use of an Ostensive Stimulus (OS): a stimulus intentionally designed to attract the attention of the audience and focus it on the meaning intended by the communicator; consequently, it is more capable than any other stimulus of generating "precise and predictable" anticipations of relevance (ibid: 255).

The third key concept in RT is the presumption of Optimal Relevance (OR) which regulates the effort-effect balance:

1) An ostensive stimulus is optimally relevant to an audience iff.

a. It is relevant enough to be worth the audience's processing effort;

b. It is the most relevant one compatible with the communicator's abilities and preferences (ibid: 256).

Finally, RT suggests a comprehension procedure for testing and constructing hypotheses about the meaning intended by the speaker, based on CGPR and OR. The inferential comprehension procedure, which applies at both the explicit and implicit levels, i.e. for the identification of explicated 
Figure 3: Example of the information structures of NestPs

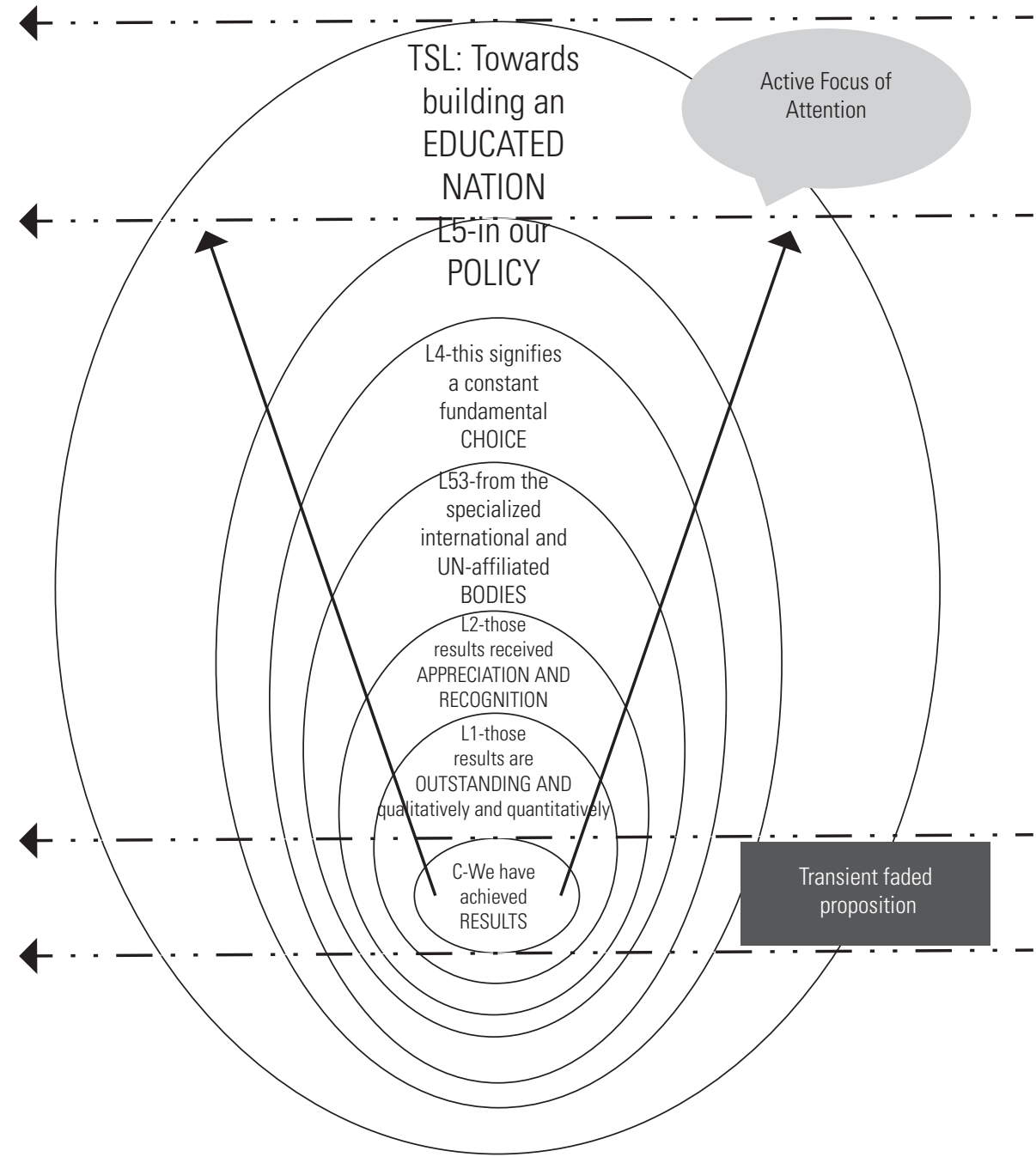

content and explicatures, and the recovery of implicatures, directs the hearer to:

2) a. Follow a path of least effort in computing cognitive effects: Test interpretive hypotheses (disambiguations, reference resolutions, implicatures, etc.) in order of accessibility.

b. Stop when your expectations of relevance are satisfied (ibid: 259).

\subsubsection{Definition of NestPs}

NestPs are cognitively taxing information structures which nest several layers of participant-new-information contents
(NI) that are ideological, unshared by the hearer and not satisfied by the objective context; take their truth value for granted; build upon them; and package them in linguistic structures that are typically associated with participant-old information (OI), in order to deliberately manipulate the hearer.

In other words, NestPs are difficultto-process information structures that are strategically devised to carry, flash, then hide several propositions that are neither substantiated nor shared by the hearer. Nevertheless, the speaker presents those 
NI contents as true, OI, common knowledge and tactically casts them in linguistic structures associated with shared OI, in order to implicitly sell them to the hearer in a manipulative linguistic transaction. Moreover, NestPs are manipulative not only because they disguise NI in the form of OI by carrying the former in structures typically associated with the latter, but also because NestPs attack the cognitive system of the hearer with multiple such structures at the same time, which results in cramming the short-term and working memories of the hearers, dissipating their processing capacities, and preventing them from evaluating the presupposed propositions properly, as will be explained in detail in the following section.

\subsection{Information structures (IS) and packaging in NestPs}

The structuring of information in NestPs can be best illustrated through an authentic example. Following is an extract from the first speech delivered by the ousted President of Tunisia Zine El Abidine ben Ali, on 27 December 2010, in response to the Arab Spring Jasmine Revolt in Tunisia:

, Example (1): While we have achieved outstanding results in the field of education, qualitatively and quantitatively, which received appreciation and recognition from specialized international and UN-affiliated bodies, this indeed signifies a constant, fundamental choice in our policy of building an educated nation.

In terms of message segmentation, the nuclear constituent of NestPs is the Core (C), which corresponds in Example (1) to the proposition "we have achieved outstanding results". The Core is the most dubious and problematic proposition in a NestPs construct; it does not have a truth value, nor does it constitute a common ground. That is the reason why the speaker tactically buries the Core as deeply as possible at the bottom of NestPs, as visually illustrated in Figures (2) and (3). All the subsequent presumptive additions can be thought of as propositional Layers (L\#) accumulated to cover the dubious Core, by pushing it further back, far from the active processing of the Focus of Attention (FOA). Those layers also act as post-modifiers that take the truth value of the Core for granted and build upon it. In Example (1), those are L1, L2, L3, L4, and L5. The highest layer of NestPs is called the Top Surface Layer (TSL). Since it is the last proposition the hearer receives and hence the most active in her/his FOA, TSL needs to have unproblematic content. In Example (1), TSL corresponds to "building an educated nation".

In terms of packaging, the two main strategies of NestPs for assigning degrees of prominence and (or) subordination to constituent presuppositions is foregrounding and (or) backgrounding, respectively. The core, being the most dubious proposition, is assigned the least possible degree of prominence by being buried inside multiple embedded presuppositions and consequently backgrounded and relegated to the back of attention and processing. On the other hand, the TSL which constitutes an unproblematic part of the common knowledge of the speaker and the hearer is foregrounded and fronted to attention, processing, and evaluation. As Figure (3) illustrates, gradation in colour and font refers to the different Layers of presuppositions nested deliberately to background the Core and foreground the TSL.

\subsection{Illustrative example of NestPs}

Following is a longer and more illustrative example of NestPs, extracted from the same speech of ousted President ben Ali:

Example (2): While the trigger of these events was one social case, whose circumstances and psychological factors we understand, we feel sorry for the damages that resulted from those events and took exaggerated dimensions, due to the political exploitation of some parties who do not want the good for their homeland, and resort to some foreign television channels that are hostile to Tunisia and broadcast lies and fallacies without scrutiny, adopting exaggeration, incitation and media defamation, all these call upon us to clari- 
Table 2: Detailed analysis of the constituent presuppositions of NestPs in example (2)

\begin{tabular}{|c|c|c|c|c|}
\hline & Utterance & Presuppositional trigger & Presupposition & $\begin{array}{l}\text { Type of presuppo- } \\
\text { sition }\end{array}$ \\
\hline 1 & These events & Definite NP (Demonstrative $+N$ ) & »There exist events; & Specific Existential \\
\hline 2 & The trigger & $\begin{array}{l}\text { Definite NP (definite article + N) } \\
\text { Temporal Clause (While + NP) }\end{array}$ & "There exists a trigger of these events; & Specific Existential \\
\hline 3 & $\begin{array}{l}\text { whose circumstanc- } \\
\text { es and psychological } \\
\text { factors we under- } \\
\text { stand }\end{array}$ & $\begin{array}{l}\text { Possessive relative pronoun } \\
\text { "whose" } \\
\text { Factive epistemic verb } \\
\text { "understand" }\end{array}$ & $\begin{array}{l}\text { "That trigger has circumstances and } \\
\text { psychological factors; } \\
\text { "We understand the afore-mentioned } \\
\text { circumstances and factors; }\end{array}$ & $\begin{array}{l}\text { Specific Existential } \\
\text { Factive Epistemic }\end{array}$ \\
\hline 4 & $\begin{array}{l}\text { Feel sorry about } \\
\text { the damages that } \\
\text { resulted }\end{array}$ & $\begin{array}{l}\text { Factive emotive verb } \\
\text { "feel sorry" }\end{array}$ & $\begin{array}{l}\text { "The above-mentioned events resulted in } \\
\text { damages } \\
\text { "We feel sorry for those damages }\end{array}$ & Factive emotive \\
\hline 5 & $\begin{array}{l}\text { and took exaggerat- } \\
\text { ed dimensions }\end{array}$ & $\begin{array}{l}\text { Change-of-state verb } \\
\text { "exaggerate" }\end{array}$ & "those damages were exaggerated & Other \\
\hline 6 & $\begin{array}{l}\text { due to the political } \\
\text { exploitation }\end{array}$ & $\begin{array}{l}\text { Definite NP } \\
\text { (definite article + NP) }\end{array}$ & $\begin{array}{l}\text { "There exists a political exploitation which } \\
\text { caused the aforementioned exaggeration }\end{array}$ & Specific Existential \\
\hline 7 & of the situation & $\begin{array}{l}\text { Definite NP } \\
\text { (definite article + NP) }\end{array}$ & $\begin{array}{l}\text { "There exists a situation that was } \\
\text { politically exploited }\end{array}$ & Specific Existential \\
\hline 8 & by some parties & Determiner + NP & $\begin{array}{l}\text { "There exist some parties who exploited } \\
\text { that situation politically }\end{array}$ & $\begin{array}{l}\text { Non-Specific Exis- } \\
\text { tential }\end{array}$ \\
\hline 9 & $\begin{array}{l}\text { who do not want } \\
\text { the good for their } \\
\text { homeland }\end{array}$ & Relative clause & $\begin{array}{l}\text { "Those parties do not want the public good } \\
\text { of their country }\end{array}$ & Other \\
\hline 10 & $\begin{array}{l}\text { some foreign televi- } \\
\text { sion channels }\end{array}$ & Determiner + NP & $\begin{array}{l}\text { "There exist foreign TV channels to which } \\
\text { the above-mentioned parties resort }\end{array}$ & $\begin{array}{l}\text { Non-Specific Exis- } \\
\text { tential }\end{array}$ \\
\hline 11 & $\begin{array}{l}\text { which broadcast lies } \\
\text { and fallacies }\end{array}$ & Relative clause & $\begin{array}{l}\text { "There are lies and fallacies broadcast by } \\
\text { those channels }\end{array}$ & Other \\
\hline 12 & $\begin{array}{l}\text { Clarify some of the } \\
\text { issues and confirm } \\
\text { some the facts } \\
\text { that should not be } \\
\text { overlooked }\end{array}$ & $\begin{array}{l}\text { Factive Epistemic verbs } \\
\text { "clarify \& confirm" } \\
\text { Definite NP } \\
\text { "the issues \& the facts" } \\
\text { Relative clause }\end{array}$ & $\begin{array}{l}\text { "There exist issues } \\
\text { "There exist facts } \\
\text { "Some of those issues and facts are neither } \\
\text { clear not confirmed } \\
\text { "Those issues and facts are overlooked }\end{array}$ & Specific Existential \\
\hline
\end{tabular}

fy some issues and confirm some facts that should not be overlooked. ${ }^{1}$

The Core of this twelve-Layer NestPs is the Specific Existential presupposition triggered by the definite NP (Demonstrative $+\mathrm{N}$ ) which assumes that ",there exist events". Here, the ousted President of Tunisia is employing presupposition ideologically and manipulatively, not only to present his view as a taken-for-granted common ground, but also to build upon it. He is

1 The quote might sound awkward in English, because I retained the original Arabic structure of the utterance in the English translation. reducing the Revolution of the Tunisian people to mere "events", attributing those "events" to a single "one social case" which he considered unworthy of explication and employing the thickest type of implicature, i.e. Particularized Implicature, to implicate that "one social case" and gloss over it in a vague manner.

That "one social case" which ben Ali implicated was the 26-year-old Tunisian man Tarek al-Tayeb Muhammad Bouazizi, who was supporting his family by selling fruit and vegetables, until a policewoman confiscated his cart, slapped him in the face and beat him up when he objected. Bouazizi went to the police station and 
the municipal council to file a complaint against the policewoman, but no official agreed to listen to him. He then doused himself in paint thinner and set himself on fire in front of the local municipal council of the town of Sidi Bouzeid (Rifai 2011; de Rosa 2011; al-Karama Forum 2011). His death gave momentum to the Tunisian revolution which ousted ben Ali twenty-eight days later and triggered the domino effect of the Arab Spring revolutions in Egypt, Libya, Yemen, Bahrain and Syria.

In the following Layers of NestPs, the ousted President uses the Definite NP (Definite article $+\mathrm{N}$ ) together with the Temporal Clause (While $+\mathrm{NP}$ ) to trigger the specific existential presupposition "There exist a trigger of those events". This presupposition performs the function of mitigation.

Ben Ali then uses the Possessive Relative pronoun "whose" to trigger the Specific Existential presupposition "There exist circumstances and psychological factors for that trigger" and follows it with a Factive Epistemic verb to trigger the presupposition that ",We understand those factors". He also uses the Factive Emotive verb phrase "feel sorry" to trigger the presupposition that ",The events resulted in damages". The last three presuppositions of the Ousted President act as an indirect acknowledgement of the problem and perform a reconciliatory function, sending the message to the revolutionaries that he is following the situation, knows what is going on and feels remorse. He then uses the Change-of-State verb "exaggerated" to trigger the presupposition that ",Those damages are exaggerated", and the Definite NP (Definite Article + NP) to trigger the Specific Existential presupposition that ",There exists a political exploitation which caused that exaggeration".

Ben Ali, then, identifies the sphere where exploitation happened and the exploiters who did it: using the Genitive Structure (of $+\mathrm{NP}$ ) to trigger the Specific Existential presupposition ",There exists a situation that was politically exploited", the (Determiner + NP) structure to trigger the Non-Specific Existential presupposition that "There exist some parties who exploited the situation politically" and the non-restrictive Relative Clause structure to trigger the presupposition that ",Those parties do not want the public good of their country". The Ousted President, then, uses the (Determiner + NP) structure to trigger the Non-Specific Existential presupposition that "There exist foreign TV channels" to which the aforementioned exploiting parties resort. He describes what those channels broadcast by using the non-restrictive Relative Clause structure to trigger the presupposition that "There are lies and fallacies broadcast by those channels". All the previous seven presuppositions perform the functions of attacking, defaming and demonizing opponents.

Finally, in the TSL, the Ousted President employs the Definite NP, the Relative Clause and the Factive Epistemic verb structures to trigger the Specific Existential presuppositions that "There exist issues and facts that are overlooked, not confirmed and not clarified".

NestPs were employed in this utterance, by the ousted President, ideologically and strategically, in order to disguise unsubstantiated, unshared propositions and present them as true, common-ground, presupposed facts. NestPs mitigated the political situation in Tunisia, by reducing the revolution of the whole country to mere "events" that were triggered by a single "one social case"; covered the highly sensitive and mobilizing story of the self-immolation of Bouazizi, by dehumanizing him, reducing him to a "case", further minimizing that case to a single one case, undermining the credibility of Bouazizi by depicting him as a mentally ill man; described all the revolutionaries as traitors conspiring with foreign media against their own country and legitimized the interference of ben Ali as the source of clarification.

The ousted President used all the above-mentioned presupposed propositions as taken-for-granted premises and built upon them to legitimize himself and what he was doing. NestPs, in this short utterance, have thus performed the multiple manipulative functions of mitigation, 
Other-dehumanisation, Other-demonization and Self-legitimisation.

\section{NestPs as a manipulative type of informative presuppositions}

Based on the premise that the presuppositions assuming specific propositions which implicitly transmit value-judgemental conceptions about how the world is and how it should be are to be considered ideological (Sbisà 1999: 492), NestPs are ideological. The fact that not all ideological propositions are manipulative leaves NestPs at the crossroads of two potential paths: being classified as informative or as manipulative. This fundamental issue can be settled in light of the pragmatic definitions of informative presupposition, the Gricean Maxims and Conditions of Quantity, Quality, Manner and Sincerity and the principles of Relevance Theory.

\subsection{Pragmatic definitions of informative presupposition}

Pragmatically speaking, Brown and Yule (1983) stipulate that presuppositions can communicate new unshared information if that information is neither "controversial" nor "asserted". In a similar vein, Stalnaker states that the definition of presupposition, in terms of common-ground, is valid in "normal, straightforward serious conversational contexts where the overriding purpose of the conversation is to exchange information" (1974: 474). None of these three conditions is satisfied in NestPs: which communicate highly controversial information, in contexts that are far from being straightforward, for purposes that have nothing to do with exchanging information.

NestPs also violate two important conditions specified by Stalnaker as defining characteristics of informative presupposition: the speaker should not "have any particular mental attitude towards the proposition" nor should they "assume anything about the mental attitudes of others in the context" (1972: 387). The fact that the speaker employs NestPs in order to manipulate the cognitive processing sys- tem of the hearer entails necessarily that the speaker does have not only a mental attitude towards his presupposed propositions, but also a deliberate intent to manipulate the mental attitudes of the hearer.

\subsection{Gricean maxims}

In terms of Gricean pragmatics, NestPs violate more than one maxim at the same time. They first violate the Gricean Maxim of Quantity, by nesting many layers of presuppositions and consequently providing more information than required. NestPs also violate the Maxim of Quality, by presupposing unsubstantiated propositions and taking their truth for granted. Moreover, NestPs violate the Maxim of Manner, by being neither clear, nor brief, nor orderly. Finally, NestPs violate the Sincerity Condition, as the speaker knows that the content of the propositions he is assuming is unsubstantiated and unshared by the hearer; nevertheless, the former strategically presupposes the propositions, as true and shared common knowledge, in order to the manipulate the latter.

The fact that NestPs violate the pragmatic definitions of informativeness and the Gricean maxims of communication eliminates the possibility of their being informative and renders them manipulative. The sense of manipulation meant here is that defined by Rigotti as:

\footnotetext{
A message is manipulative if it twists the vision of the world (physical as well as social - or human - actual as well as virtual) in the mind of the addressee, so that he/she is prevented from a healthy attitude towards decision. (i. e., an attitude responding to his/her very interest), and pursues the manipulator's goal in the illusion of pursuing her/his own goal (2005: 68)
}

This definition is in line with the argument advanced by van Dijk that the discourse employed to reproduce power, exercised discursively in the interest of the powerful and against that of the powerless, is an ideological and manipulative discourse (2006: 360).

In NestPs, the speaker commits the hearers to his views, provides them with 
unsubstantiated information with which they are unlikely to agree in normal circumstances and manipulates their cognitive systems in order to achieve the strategic goal of maintaining unequal relations of power. NestPs are thus inherently ideological and manipulative.

\section{Manipulative information structures and cognitive mechanisms of NestPs}

The manipulation of NestPs can be problematized and accounted for relevance-theoretically in terms of information structures and cognitive mechanisms.

\subsection{Information structures}

\subsubsection{Ostensive Stimulus (OS)}

An OS "conveys a presumption of its own optimal relevance", i.e. it is engineered to behave as the strongest stimulus most capable of attracting the attention of a targeted audience and focusing it on the specific meaning intended by the speaker (Wilson \& Sperber 2004: 254). In NestPs, the TSL functions as the OS which the speaker baits in order to trigger anticipations of optimal relevance in the cognitive systems of his audience, enticing them to assume that the TSL is the strongest and most relevant stimulus, and consequently the most rewarding one to process.

The first manipulative aspect of NestPs thus lies in the fact that their TSL does not qualify for the position it occupies as the OS worthy of foregrounding and processing. This is because the TSL is not optimally relevant: it is not the most relevant stimulus "compatible with communicator's abilities and preferences" (ibid: 256) and it is not the stimulus most capable of generating "precise and predictable" anticipations of relevance; consequently, it is not the strongest stimulus most worthy of processing. TSL is in fact a weak stimulus whose positive cognitive effects do not compensate for the effort required for processing it; thus, it should not have been foregrounded in the position it occupies.

\subsubsection{Cognitive Principle of Relevance (CGPR)}

NestPs are also manipulative because they exploit the universal tendency towards the maximisation of relevance, as informed by the CGPR, i.e. the human tendency to select the most optimally relevant stimulus in the environment and process it (ibid: 249). This manipulative exploitation is also performed by designing the TSL to act as the salient OS, and foregrounding it in the way that most attracts the attention of the targeted audience and best prompts the retrieval of specific contextual assumptions that warrant yielding the exact conclusion intended by the speaker. NestPs thus do not only anticipate the cognitive behaviour of the targeted audience, but also frame, channel and direct it strategically in order to achieve specific manipulative goals.

\subsubsection{Optimal Relevance (OR)}

NestPs are also manipulative because they violate the concept of OR, not only by their TSL, as explained above, but also by their other sub-structures. According to OR, it is in the best interest of the speaker, if they would like to communicate successfully with an audience, to formulate their message in the easiest and most cognitively accessible, economic and consequently rewarding manner to that audience. The speaker is also obliged to substantiate any claims they make with the evidence necessary to achieve the intended cognitive effects in the audience.

NestPs do not fulfil any of these conditions: The producer of NestPs tactically segments, arranges, and packages the message in a deliberately-convoluted and hard-to-process manner that backgrounds and buries the strongest proposition most worthy of processing, i.e. the Core, and foregrounds and assigns the highest degree of prominence to the weakest and least relevant stimulus, i.e. the TSL. This manipulative ordering enables the producer of NestPs to create a groundless, deceptive air of agreement with their audience, by hiding the most controversial proposition, flashing the shared one, and embedding, nesting, and disguising mul- 
Figure 4: Structure-content cognitive conflict in NestPs

Long-Term Memory

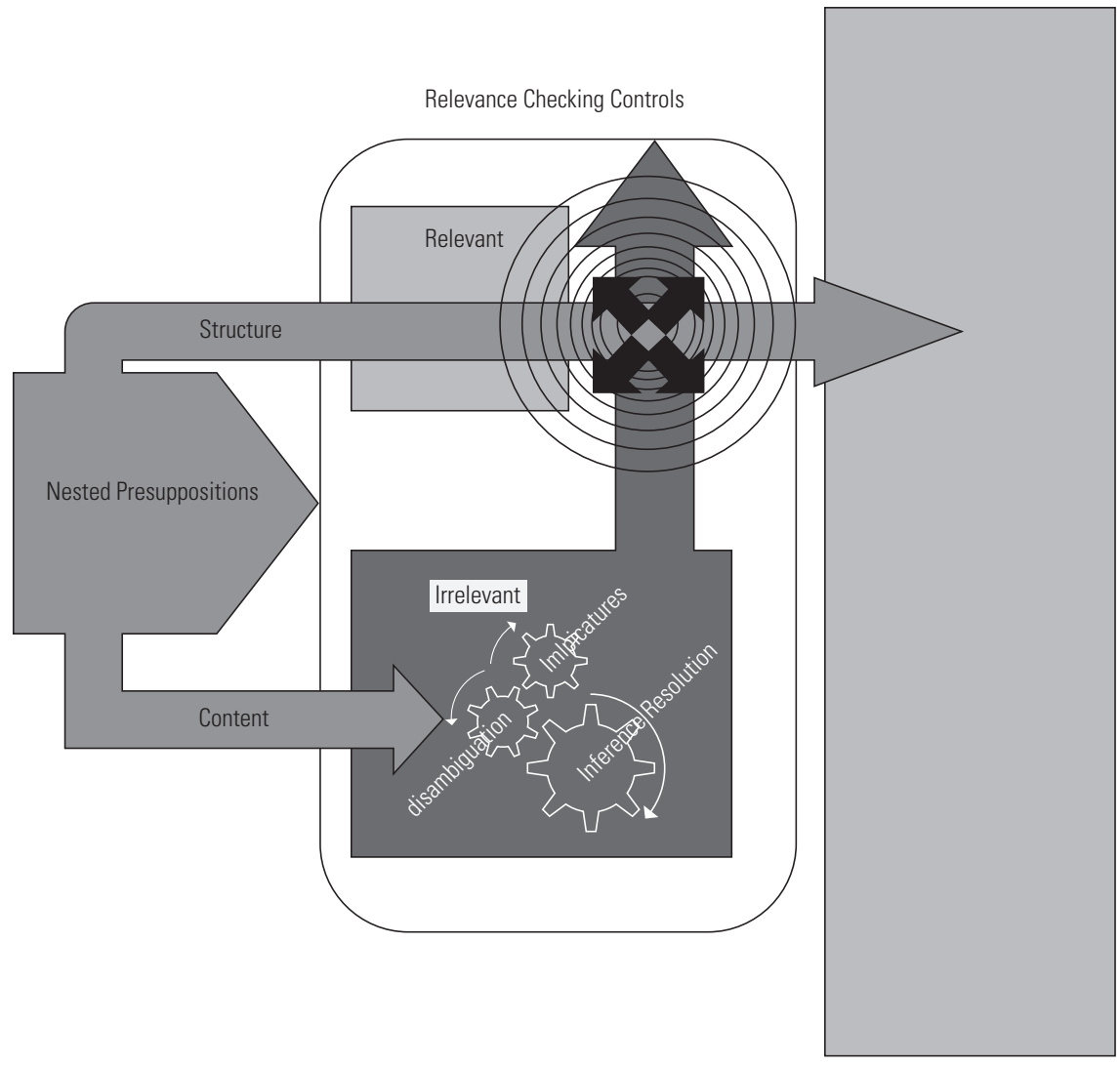

tiple, unsubstantiated presuppositions in between, without establishing the truth values of any of them.

\subsection{Cognitive (Mis) Behaviour of NestPs}

\subsubsection{Structure-content cognitive conflict (SCCC)}

Since pragmatic presuppositions are participant-old information shared by the interlocutors, they behave cognitively as backgrounded information that is not currently under active processing and do not go through the filters of relevance or the checks of further discussion (Simons 2004; von Fintel 2008; de Saussure 2012).

NestPs, on the other hand, consist mainly of participant-new active information (NI) that is twisted to act as presup- positions by being carried in structures associated with old-information (OI). This forced imposition of NI content in OI structures is likely to cause logical and cognitive conflict in the minds of the hearers. This conflict, which can be termed Structure-Content Cognitive Conflict (SCCC), results from the situation when the old-information structures of NestPs are readily classified as relevant and prepared to be admitted into the long-term memory, while their new-information contents are still being processed, i.e. classified as new, disambiguated, explicated, inferentially resolved, checked for reconciliation against their old-information structures, etc., and ultimately classified as irrelevant. Figure (4) attempts to depict this SCCC visually. 
Resolving this SCCC is cognitively taxing, in terms of the processing efforts it consumes at the expense of the overall processing capacity. SCCC thus causes a deficiency in the cognitive processing capacity of the hearer, which in turn incapacitates their cognitive checks, filters and controls allowing the unsubstantiated propositions and implausible arguments carried by NestPs to bypass those checks and filters and be admitted into the longterm memory.

\subsubsection{Minimum effort path (MEP)}

According to clause (b) of the definition of OR in [1], the speaker is expected to formulate their message in the easiest way their audience can understand. On the other end of the OIC situation, the hearer is entitled to follow a path of minimum effort and to stop processing upon reaching the first plausible interpretation that satisfies their expectations of relevance, as suggested by clauses (a) and (b) of the comprehension procedure in [2] (Wilson \& Sperber 2004: 256-259). Moreover, given the inverse relationship between relevance and effort in RT, the first and most easily constructed interpretation is most likely to enjoy the status of optimal relevance, because the speaker is expected to have cooperated and formulated his utterance in such an easy way that the first interpretation to strike the cognitive effort-effect balance, in the hearer, is to be deemed the one intended by the supposedly cooperative speaker.

In violation of clause (b) of the definition of OR in [1], the producer of NestPs tactically formulates their message in a complex and difficult-to-process manner: embedding many presuppositions in a large, deep nest; disguising and wrapping NI in the structures of OI; reversing the order of accessibility by backgrounding the strong stimulus, foregrounding the weak ones, and forcing the latter to function as an OS; and taking the truth value of many unsubstantiated propositions for granted and building upon them. On the other hand, the hearer of NestPs innocently follows the minimum effort path (MEP), by testing interpretive hypotheses in their order of accessibility and stopping when his expectations of relevance are satisfied, driven by good faith in the expectation that the speaker had observed clause (b) of OR and formulated his message in the easiest and most accessible way.

As a result of these cooperatively and sincerely incompatible approaches adopted by the producer and the consumer of NestPs, the comprehension procedure in NestPs does not proceed as smoothly as informed and anticipated by RT. MEP fails to lead the hearer to construct relevant, anticipatory interpretive hypotheses that satisfy the expectations of relevance raised by the utterance itself, which imposes an extra processing load on the already strained cognitive processing system, that has been making hard attempts to solve the SCCC, and consequently dissipating more processing efforts and resources of the overall processing capacity of the hearer. This MEP failure, exacerbated by the waste of processing capacity caused by the SCCC, renders the cognitive system of the hearer vulnerable to what I call the process of Cognitive Underpassing.

\subsubsection{Cognitive Underpassing (CU)}

Cognitive Underpassing (CU) can be thought of as the total sum result of many factors that have joined forces to hamper the proper cognitive processing of the hearer: foregrounding the weak and non-optimally relevant TSL and backgrounding the strong and optimally relevant C; creating a cognitive conflict by casting NI propositional content in OI structures; accumulating many layers of finer nested presuppositions the testing and construction of whose interpretative hypotheses require complex, cognitively taxing processing; taking the truth value of those nested presuppositions for granted and building upon them without substantiation; attacking the cognitive system of the hearer with a large number of those presuppositions; manipulating the OR effort-effect formula by reversing the order of accessibility to the nested propositions; failing to establish relevance through the MEP; and wasting many processing efforts in resolving the SCCC. All these factors 
Figure 5: Cognitive underpassing in NestPs

Long-Term-Memory

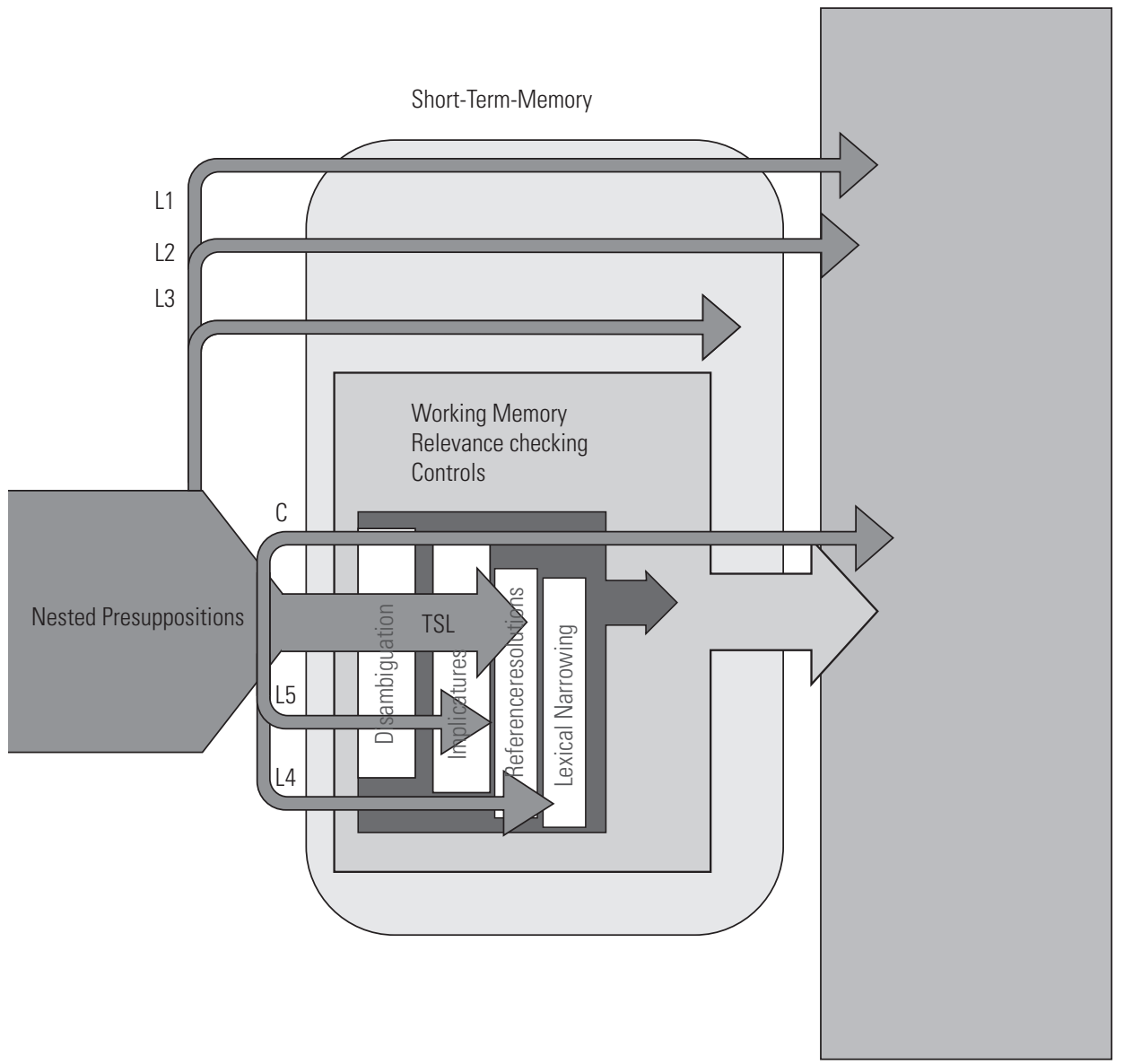

combined together can result in a processing overload which strains the cognitive processing capacity of the hearer, renders it incapable of performing any further proper processing, and allows unsubstantiated claims and propositions to bypass Relevance Checking Controls and filters and to be accepted as relevant.

In other words, this Cognitive Underpassing process takes place when the processing capacity of the hearer fails to handle the cognitive processing load caused by (1) the information structures, (2) the fallacious contents, and (3) the cognitive behaviour of NestPs, as visually illustrated in Figure (5). As a result, the Short-Term Memory and the Working Memory get gradually crammed and overstrained, until no processing capacity is left to check or verify incoming presuppositions. It is at that point that the Layers of NestPs take advantage of their structure, as already-relevant, low-cost, effect-producing, old-information, in order to bypass the truth/falsity and relevance-checking controls of the hearer and get admitted into their Long-Term Memory, as presupposed, checked, relevant propositions, with substantiated truth value.

To sum up, and based on the definition developed by Leech (1983: 60) that a “textually 'well-behaved' utterance being one which anticipate and facilitate H's [the hearer's] task in decoding, or making sense 
of, the text", NestPs are linguistically, pragmatically, and cognitively misbehaved utterances: they are strategically engineered to manipulate the cognitive processing systems of the hearers. Manipulation is therefore an inherent characteristic of the propositional content, information structures, cognitive behaviour, and pragmatic functions of NestPs. It can be thus confidently concluded that NestPs are a manipulative form of informative presupposition.

\section{Conclusion}

This paper has introduced the new pragmatic concept of NestPs and sketched a relevance-theoretic account that explains its manipulative character and dynamics, in terms of its information structures, contents and cognitive processing mechanisms.

The paper began by laying some necessary theoretical foundations: exploring different approaches to pragmatic presupposition, compiling a taxonomy of the types of presupposition and their triggers, discussing some of the most problematic properties of pragmatic presupposition and situating the proposed concept of NestPs in the wider context of current pragmatic theory, by identifying and critiquing research gaps in four of the most relevant studies in the field. A conclusion was drawn that none of the existing definitions of pragmatic presupposition can adequately capture the manipulative characteristics and mechanisms of NestPs. The two theoretical frameworks of Textual Rhetoric and Relevance Theory, within which the new concept is immediately embedded, were also briefly discussed and followed by a definition of NestPs, illustrated with four authentic examples.

The relationship between NestPs, on the one hand, and informativeness and manipulation, on the other, was problematized, on pragmatic, Gricean and relevance-theoretic grounds, leading to the conclusion that NestPs are inherently manipulative. A cognitive account was developed to explain the manipulative charac- ter and behaviour of NestPs, in terms of the relevance-theoretic concepts of Ostensive Stimulus, Cognitive Principle of Relevance, Optimal Relevance, Comprehension Procedure, in addition to the newly suggested cognitive mechanisms of Cognitive Underpassing and Structure-Content Cognitive Conflict.

The manipulative character and function of NestPs were therefore established in terms of propositional content, information structures, packaging, cognitive mechanisms, and logical fallaciousness: NestPs carry new unsubstantiated propositional content, strategically arranged in a complex and convoluted order and cast in structures typically associated with the opposite kind of content, in order to deliberately hamper the proper cognitive processing of the hearer.

In conclusion, I borrow what Wilson and Sperber said about their well-developed theory: "Relevance Theory does not provide an absolute measure of mental effort or cognitive effect, and it does not assume that such a measure is available to the spontaneous workings of the mind" (2004: 278). The same can be very humbly argued about NestPs. The research I attempted and discussed in this paper is certainly limited in scope and depth, and requires deeper and wider empirical and theoretical investigation, in order to solidify the new concept of NestPs. A good starting point could be running empirical experiments to measure the speed of processing a single pragmatic presupposition and comparing it to that of processing NestPs. Finally, presupposition "remains [...] still only partially understood, and an important ground for the study of how semantics and pragmatics interact" (Levinson 1983: 225).

\section{References}

Brown, G., \&Yule, G. (1983). Discourse analysis. Cambridge: Cambridge University Press.

Capone, A. (2017a). Presuppositions as conversational phenomena. Lingua, 198, 22-37. doi:10.1016/j.lingua.2017.06.014. 
Capone, A. (2017b). Conversational presuppositions: Presupposition as defeasible inference. Intercultural Pragmatics, 14(4), 557-583. doi:10.1515/ip-2017-0025

Chapman, S., \& Routledge, C. (1999). The pragmatics of detection: Paul Auster's city of glass. Language and Literature: Journal of the Poetics and Linguistics Association, 8(3), 241-253. doi:10.1177/096394709900800303

de Rosa, A. (2011, December 15). A 2011 timeline of protest, revolution and uprising. Retrieved from http://blogs.reuters.com/ anthon-derosa/2011/12/15/a-2011-timeline-of-protest-revolution- and-uprising/ [Accessed 24 May 2016]

de Saussure, L. (2012). Cognitive pragmatic ways into discourse analysis: The case of discursive presuppositions. Lodz Papers in Pragmatics, 8(1), 37-59. doi:10.1515/lpp-2012-0004

Fairclough, N. (1995). Critical discourse analysis: The critical study of language. London: Longman.

Forum, Al-Karama (2011, January 27). Timeline of the Tunisian Dignity Revolution. Retrieved from http://alkarama14.wapka. me/forum2_theme_615976.xhtml?te$\mathrm{ma}=10$ [accessed 31 October 2013]

Frege, G. ([1892] 1952) Über Sinn und Bedeutung. Zeitschrift für Philosophie und Philosophische Kritik, 100, 22-50. Translated by Peter Geach and Max Black as 'Sense and Reference'. In P. Geach \& M. Black (Eds.), Translations from the Philosophical Writing of Gottlob Frege (pp. 56-78). Oxford: Blackwell.

Gauker, C. (1997). Domain of Discourse. Mind, 106(421), 1-32.

Gauker, C. (1998). What is a context of utterance? Philosophical Studies, 91(2), 149-172.

Gazdar, G. (1979). Pragmatics: Implicature, presuppositions and logical form. New York: Academic Press.

Greco, S. (2003). When presupposing becomes dangerous. How the procedure of presuppositional accommodation can be exploited in manipulative discourses. Studies in Communication Sciences, 3(2), 217-234. doi:10.5169/seals-791181
Green, G. (1989). Pragmatics and natural language understanding. Hillsdale, N.J.: L. Erlbaum Associates.

Huang, Y. (2007). Pragmatics. Oxford: Oxford University Press.

Karttunen, L. (1973). Presuppositions of compound sentences. Linguistic Inquiry, 4, 169-193.

Karttunen, L. (1974). Theoretical Linguistics. In S. Davis (Ed.), (1999) Pragmatics: A Reader (pp. 406-415). Oxford: Oxford University Press.

Keenan, E. (1971). Two kinds of presupposition in natural language. In C. J. Fillmore \& D. T. Langendoen (Eds.), Studies in Linguistic Semantics (pp. 45-54). New York: Holt, Rinehart \& Winston.

Leech, G. N. (1983). Principles of pragmatics. London: Longman.

Levinson, S. (1983). Pragmatics. Cambridge: Cambridge University Press.

Lewis, D. (1979). Scorekeeping in a Language Game. Journal of Philosophical Logic, 8, 339-359.

Macagno, F., \& Capone, A. (2016a). Uncommon ground. Intercultural Pragmatics, 13(2), 151-180.

Macagno, F, \& Capone, A. (2016b). Presuppositions as cancellable inferences. In K. Allan, A. Capone, I. Kecskes (Eds.), Pragmemes and theories of language use (pp. 45-68). eBook: Springer. doi:10.1007/978-3-31943491-9

Maingueneau, D. (1996). Les Termes Clés de l'Analyse du Discours. Paris: Seuil.

Peccei, J. (1999). Pragmatics. London: Routledge.

Richardson, J. E. (2007). Analysing newspapers: An approach from critical discourse analysis. New York: Palgrave Macmillan.

Rifai, R. (2011, January 23). Timeline: Tunisia's uprising. Chronicle of nationwide demonstrations over the country's unemployment crisis. Retrieved from http:// www.aljazeera.com/indepth/spotlight/ Tunisia/2011/01/201114142223827361. html [Accessed 24 May 2016]

Rigotti, E. (2005). Towards a typology of manipulative processes. In L. de Saussure \& P. Schulz (Eds.), Manipulation and ideologies in the twentieth century: Discourse, language and mind (pp. 61-83). Amsterdam \& Philadelphia: John Benjamins. 
Sbisà, M. (1999). Ideology and the persuasive use of presupposition. In J. Verschueren (Ed.), Language and Ideology. Selected Papers from the 6th International Pragmatics Conference (pp. 492-509). Antwerp: International Pragmatics Association.

Schipper, E. \& Schuh, E. (1960). A First Course in Modern Logic. London: Routledge and Kegan Paul.

Short, M. (1989). Discourse analysis and the analysis of drama. In R. Carter \& P. Simpson (Eds.), Language, Discourse and Literature: An Introductory Reader in Discourse Stylistics (pp. 138-68). London: Unwin Hyman.

Simons, M. (2003). Presupposition and accommodation: Understanding the Stalnakerian picture. Philosophical Studies, 112(3), 251-278. doi:10.1023/A:1023004203043

Simons, M. (2004). Presupposition and Relevance. In Z. G. Szabó (Ed.), Semantics vs. Pragmatics (pp. 329-355). Oxford: Oxford University Press.

Sperber, D., \&Wilson, D. (1985). Loose talk. Proceedings of the Aristotelian Society, LXXXVI, 153-171.

Sperber, D., \&Wilson, D. (2002). Pragmatics, modularity and mind-reading. Mind \& Language, 17(1-2), 3-23. doi:10.1111/1468-0017.00186

Sperber, D., \&Wilson, D. (1995). Relevance: Communication and cognition ( $2^{\text {nd }} \mathrm{ed}$.). Oxford: Blackwell.

Stalnaker, R. (1972). Pragmatics. In D. Davidson \& G. Herman (Eds.), Semantics of Natural Language (pp. 380-397). Dordrecht \& Boston: D. Reidel.

Stalnaker, R. (1974). Pragmatic presuppositions. In S. Davis (Ed.), Pragmatics (pp. 471-481). New York: Oxford University Press.

Stalnaker, R. (1978). Assertion. In P. Cole (Ed.), Syntax and Semantics 9: Pragmatics (pp. 315-332). New York: Academic Press.
Stalnaker, R. (2011). Pragmatic presuppositions. In D. Archer \& P. Grundy (Eds.), The Pragmatics Reader (pp. 68-78). Abingdon: Routledge.

Strawson, P. (1950). On referring. Mind, 59, $230-44$

Strawson, P. (1952). Introduction to Logical Theory. London: Methuen.

van Dijk, T. (2006). Discourse and manipulation. Discourse \& Society, 17(3), 359-383.

Verschueren, J. (1999). Understanding Pragmatics. London: Hodder Arnold.

von Fintel, K. (2008). What is presupposition accommodation, again? Philosophical Perspectives, 22(1), 137-170. doi:10.1111/j.1520-8583.2008.00144.x

Waugh, L., Catalano, T., Al Masaeed, K., Do, T., \& Renigar, P. (2016). Critical discourse analysis: Definition, approaches relation to pragmatics, critique and trends. In A. Capone \& J. Mey (Eds.), Interdisciplinary studies in pragmatics, culture and society (pp. 70-135). Switzerland: Springer. eBook. doi:10.1007/9783319126166

Whately, R. (1848). Elements of Logic. London: Longmans.

Wilson, D. \& Sperber, D. (2004). Relevance Theory. In L. Horn \& G. Ward (Eds.), Handbook of Pragmatics (pp. 249-287). Oxford: Blackwell.

Wilson, D. (1998). Linguistic structure and inferential communication. In B. Caron (Ed.), Proceedings of the $16^{\text {th }}$ International Congress of Linguists (Paris 1997). Amsterdam: Elsevier.

Yule, G. (1996). Pragmatics. Oxford: Oxford University Press. 